\title{
Proteomic Analysis of Developing Somatic Embryos of Coffea arabica
}

\author{
Ângela Tonietto • Juliana Hiromi Sato • \\ João Batista Teixeira • Emanuel M. de Souza • \\ Fabio O. Pedrosa • Octávio Luiz Franco • Angela Mehta
}

Published online: 3 May 2012

(C) Springer-Verlag 2012

\begin{abstract}
Differential protein profiles of three stages of somatic embryogenesis, including globular, torpedo, and cotyledonary somatic embryos, of Coffea arabica cv. Catuaí Vermelho were analyzed in an attempt to better understand somatic embryogenesis in coffee plants. Somatic embryos at these different stages of development were collected from in vitro-grown cultures, and then macerated in liquid nitrogen. Proteins were extracted with phenol and further quantified using the Bradford method. The bidimensional electrophoresis analysis revealed a wide range of proteins ranging between 10 and $160 \mathrm{kDa}$ and of $\mathrm{pH}$ values ranging from 3 to 10 . Several differentially expressed proteins were identified by mass spectrometry, and some were found to be specific to these different stages of somatic embryogenesis in coffee. The enolase and 11S storage globulin proteins, for
\end{abstract}

\footnotetext{
Â. Tonietto $\cdot$ O. L. Franco

Centro de Análises Proteômicas e Bioquímicas

Pos-Graduação em Ciências Genômicas e Biotecnologia,

Universidade Catolica de Brasilia,

SGAN 916, Av. W5, Módulo C, sala 219,

CEP 70790-160 Brasília, DF, Brazil

J. H. Sato

Universidade de Brasília,

Campus Universitário Darcy Ribeiro,

CEP 70910-900 Brasília, DF, Brazil

J. B. Teixeira $\cdot$ A. Mehta $(\bowtie)$

Embrapa Recursos Genéticos e Biotecnologia,

Avenida W 5 Norte Final,

CEP 70770-917 Brasília, DF, Brazil

e-mail: amehta@cenargen.embrapa.br

E. M. de Souza $\cdot$ F. O. Pedrosa

Universidade Federal do Paraná, Centro Politécnico,

Caixa Postal 19046, CEP 81531-980 Curitiba, PR, Brazil
}

example, could be used as molecular markers for somatic embryo development stages and for embryogenic and nonembryogenic genotype differentiation, respectively.

Keywords Somatic embryogenesis $\cdot 2$-DE $\cdot$ Mass spectrometry $\cdot$ Protein profile $\cdot$ Molecular markers

\section{Introduction}

Coffee is one of the most important agricultural products cultivated worldwide and is of high importance for the Brazilian economy. Brazil accounts for $50 \%$ of global coffee production, together with Vietnam and Colombia, and is responsible for more than one third of the world's production and exportation (Vieira et al. 2006). Coffea arabica is the most cultivated species, occupying approximately $75 \%$ of the total area of coffee production with excellent beverage quality, and therefore it is of great importance for the coffee industry (Vieira et al. 2006). Several genetic improvement studies have been performed to obtain varieties with important agronomic traits such as tolerance to biotic and abiotic stresses, as well as higher productivity. Genetic improvement programs have delivered to coffee growers several cultivars with high productivity to attend consumer needs (Pereira et al. 2007). However, conventional breeding methods, such as hybridization, backcrosses and interspecific crosses, selection and progeny evaluation, can take over 30 years in order to obtain a new cultivar. This situation clearly shows the need to develop more accelerated propagation techniques in order to obtain new cultivars more rapidly.

Somatic embryogenesis (SE) is an important in vitro technique for the multiplication of coffee plants. This method 
consists of developing embryoids from haploid cells or somatic diploids, without gamete fusion, allowing an accelerated micropropagation of superior clones and the maintenance of interspecific hybrids (Pereira et al. 2007). SE studies have been widely performed in order to better understand the mechanisms associated to this process and help in vitro micropropagation. The differential gene expression in somatic cells is involved in developmental reprogramming of these cells, and confers the capacity to manifest the embryogenic potential (Zeng et al. 2006). SE is used to obtain a large number of plants of high economic value, genetically uniform and free from diseases. Through this approach, it is possible to obtain better adapted cultivars with a high multiplication rate when compared to other propagation methods. It is also possible to transfer genes and therefore, this method is frequently used in genetic improvement studies of clonal propagation.

The objective of this work was to analyze the differential protein profile of $C$. arabica cv. Catuaí Vermelho by using a combination of bidimensional electrophoresis (2-DE) and mass spectrometry (MS) technologies in three different SE stages (Torpedo, Globular and Cotyledonar) in order to better characterize the SE process of this species.

\section{Materials and Methods}

\section{Induction of Somatic Embryogenesis}

The third leaf pair (from top to bottom) of "Catuaí Vermelho" plants maintained in greenhouse conditions was collected, cleaned with alcohol $70 \%$ and sodium $2 \%$. Leaf sections of $0.5 \mathrm{~cm}^{2}$ were cut and inoculated in Petri dishes containing culture medium $\mathrm{C}$ according to Boxtel and Berthouly (1996), with an increased 2,4-dichlorophenoxyacetic acid (2,4-D) concentration of $20 \mu \mathrm{M}$. After 1 month, the explants were transferred to new plates containing the culture medium $\mathrm{C}$ with a reduced concentration of 2,4-D $(10 \mu \mathrm{M})$. The explants were maintained in this medium for 3-4 months until the formation of embryogenic sectors. These sectors were isolated from the original explants, cultivated in liquid $\mathrm{C}$ medium with a 2,4-D concentration of $5 \mu \mathrm{M}$, and maintained in this medium for cellular mass increase. A part of this mass was transferred to a modified $\mathrm{C}$ medium in which 2-isopentenyl adenine (2-iP), indole-3butyric acid (IBA) and 2,4-D were replaced by 6benzyladenine (BA) $10 \mu \mathrm{M}$ and napthalene acetic acid (NAA) $2.5 \mu \mathrm{M}$ for differentiation over a period of 1 month. The globular embryos were then transferred to a new flask containing the same medium for the formation of the torpedo embryos. These embryos were placed in the EG medium (Boxtel and Berthouly 1996) for maturation and formation of cotyledonary embryos.

\section{Protein Extraction}

Each sample was separately ground in liquid nitrogen and total proteins were extracted according to de Mot and Vanderleyden (1989) from at least three different experiments. Approximately $0.1 \mathrm{~g}$ of ground tissue was placed in a $1.5-\mathrm{ml}$ Eppendorf tube with $1 \mathrm{ml}$ extraction buffer consisting of $0.7 \mathrm{M}$ sucrose, $0.5 \mathrm{M}$ Tris- $\mathrm{HCl}, 30 \mathrm{mM} \mathrm{HCl}, 50 \mathrm{mM}$ EDTA, $0.1 \mathrm{M} \mathrm{KCl}$ and $40 \mathrm{mM}$ DTT. An equal volume of phenol was added and after 15 min of vigorous shaking, the samples were centrifuged at $4,000 \times g$ and re-extracted twice with the extraction buffer. Proteins were precipitated in 5 volumes of $0.1 \mathrm{M}$ ammonium acetate in chilled methanol at $-20^{\circ} \mathrm{C}$ for $2 \mathrm{~h}$. Precipitates were washed in acetone and resuspended in $40 \mu \mathrm{L}$ of rehydration buffer consisting of $2 \%$ CHAPS, $8 \mathrm{M}$ urea, $2 \mathrm{M}$ thiourea, $1 \%$ dithiothreitol (DTT), traces of bromophenol blue and $1 \%$ IPG Buffer. The total protein content was estimated according to Bradford (1976).

\section{Gel Electrophoresis Analyses}

Isoelectric focusing and molecular mass separation were conducted according to Görg et al. (1988) using $11-\mathrm{cm}$ immobilized $\mathrm{pH}$ gradient (IPG) strips with a $\mathrm{pH}$ range of 3-10 and a Multiphor II electrophoresis system (GE HealthCare). Strips were hydrated in $250 \mu$ of rehydration buffer for $16 \mathrm{~h}$. The strips were then maintained in equilibration buffer (Tris-HCl 1.5 M pH 8.8; Urea $6 \mathrm{M}$; Glycerol $30 \%$; SDS $2 \%$; bromophenol blue $1 \%$ ) with 1 M DTT for $15 \mathrm{~min}$ followed by $15 \mathrm{~min}$ in the same buffer containing $2.5 \%$ iodoacetamide. The second dimension was performed as described by Laemmli (1970) in $16 \times 16 \mathrm{~cm}$ SDS-PAGE using $12 \%$ acrylamide gels and the molecular mass marker "Benchmark Protein Ladder" (Invitrogen). Gels were stained with silver nitrate according to Blum et al. (1987) or with Coomassie blue and each protein sample was analyzed in triplicate.

\section{Image Analysis}

Three 2D gel images from each sample were analyzed using the Bionumerics software v. 4.6 (Applied Maths NV, Belgium). First, a calibration with a grey scale was performed to transform grey levels into optical density (OD) values for each pixel (px) of the gel image. The gel pictures were analyzed as tiff files and the wizard detection method proposed by the software was used to detect the spots with the following parameters: $30 \mathrm{px}$ for estimated spot size, $3 \mathrm{px}$ for minimum spot size and a spot contrast enhancement of $75 \%$. Automatically detected spots were manually checked, and some of them were manually added or removed. 
Following the detection procedure, the normalization step was carried out to attribute a common spot identity for the same spots derived from different images using the reference gel construct and automatically matching options of the Bionumerics software. The overlapped images were based on landmark spots showing same $\mathrm{p} I$ and $M_{\mathrm{w}}$ in both gels. A regression curve was generated according to the spot volumes to analyze the overlapping efficiency. Statistically validated differential spots observed in Coomassie-stained gels were excised from the gels for trypsin digestion and mass spectrometry analysis.

\section{Trypsin Digestion and Mass Spectrometry Analysis}

Proteins were excised from the 2D gels and enzymatically digested into peptide fragments using Trypsin Gold (Promega) according to Shevchenko et al. (1996). Aliquots of each hydrolysate sample were mixed with a saturated matrix solution of $\alpha$-cyano-4-hydroxycinnamic acid, spotted onto MALDI target plates, and allowed to air dry. Monoisotopic masses of the molecular components ranging from $\mathrm{m} / \mathrm{z} 600$ to 6,000 were determined by mass spectrometry using an UltraFlex II MALDI-TOF/TOF (Bruker Daltonics, Bilerica, MA) or a 4700 MALDI-TOF/TOF (Applied Biosystems, Framingham, MA) controlled by the manufacturer's software. All spectra were obtained in a positive reflector mode, using an accelerating voltage of around $20 \mathrm{kV}$ for MS mode. Molecular ions displaying sufficient signal were submitted to MS/MS analyses, carried out in the positive mode precursor ion fragmentation at a laser frequency of $50 \mathrm{~Hz}$. The MS/MS spectra were acquired in the reflector positive mode after collision induced dissociation (CID) or LIFT'M (Bruker Daltonics) fragmentation with external calibration. Resulting data were analyzed using FlexAnalysis 2.4 or Data Explorer 4.5 and MS/MS spectra were further interpreted automatically and manually (de novo sequencing) using the PepSeq software running under MassLynx 4.0 (Micromass, Manchester, UK). Peptide masses obtained were used for identification by the Mascot program (Matrix Science, London, UK) using the NCBI database. Peptide sequences obtained by de novo sequencing were analyzed using the Blast program.

\section{Results and Discussion}

The 2D protein maps of coffee somatic embryos in the different embryogenic stages were analyzed in this study. The gels were stained with silver nitrate and revealed proteins varying in size from 10 to $160 \mathrm{kDa}$ and in $\mathrm{pH}$ from 3 to 10 . The number of spots was determined by the Bionumerics software v. 4.6 (Applied Maths NV) and approximately 120 proteins could be clearly visualized in each gel (Fig. 1). It is possible that this number may be an underestimation of
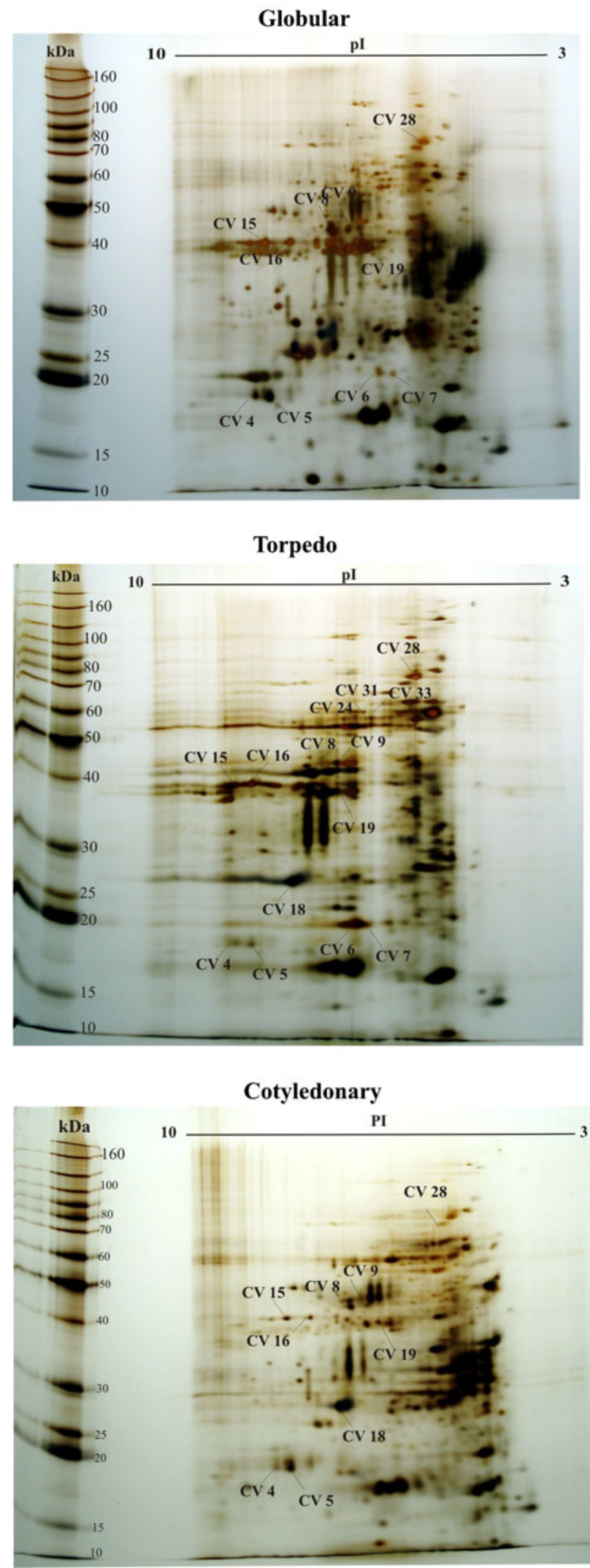

Fig. 1 2-DE protein profiles of different somatic embryos of Coffea arabica cv. Catuaí Vermelho. Somatic embryos in the globular (a), torpedo (b) and cotyledonary (c) phases. Protein spots indicated in the gels were identified by mass spectrometry 
the total spots present in the gel due to difficulties in determining the spot area for some proteins, especially in the basic region. The agglomeration of some groups of proteins is a common event in these types of tissues and was observed in all repetitions. The areas where spot volume could not be accurately calculated were not considered in the differential analysis.

The comparison of the three protein maps of the embryogenic stages revealed several differentially expressed proteins and those visualized in Coomassie blue-stained gels were excised and analyzed by mass spectrometry. Table 1 shows the 14 proteins identified by this method as well as their relative expression, evaluated by the mean value of the "spot relative volume", as determined by the Bionumerics software v. 4.6 (Applied Maths NV). The general analysis of the protein profiles of the three somatic embryogenic phases also showed that the torpedo stage presented a more differentiated protein expression, since a higher number of exclusive proteins were visualized in this phase (Fig. 2).

$\mathrm{SE}$ is used in plant tissue culture for the development of embryos from somatic cells in response to an external signal, which triggers several biochemical changes in the cell. A genetic reprogramming of gene expression occurs, resulting in cell division. During SE, several genes are induced in the transition from disorganized cell growth to embryonary development, including those related to stress (Fehér et al. 2003). Some genes have been associated to the induction of $\mathrm{SE}$, such as the receptor-like kinases (SERK), which have been isolated from different plants (Huang et al. 2010; Ma et al. 2012; Yang et al. 2011). Although information on gene expression during SE has been increasingly accumulated, the molecular changes that occur are not yet well understood.

The proteomic approach has been widely used to better understand the somatic embryogenic process and several differentially expressed proteins have been recently reported (Bian et al. 2010; Li et al. 2010; Sharifi et al. 2012). In our study, proteins associated to energy production were identified, such as ribulose biphosphate carboxylase/oxygenase (Rubisco) (spot CV 33), enolase (spot CV 24), 2,3-bisphosphoglycerate-independent phosphoglycerate mutase (spot 31 ) and glyceraldehyde-3-phosphate dehydrogenase (GAPDH) (spot CV 16), which are essential for glycolysis and glycogenesis. In developing secondary embryos of cassava (Manihot esculenta), the abundance of proteins related to energy metabolism was attributed to the high metabolic activity that is necessary to maintain intense cell division activity in the developing embryos (Baba et al. 2008).

Enolase, one of the protein spots identified in this study, is a glycolytic enzyme that catalyses the reversible conversion of 2-phospho-D-glycerate to phosphoenolpyruvate (PEP) (Wold and Ballou 1957; Van der Straeten et al. 1991). Enolase is also part of gluconeogenesis and therefore is important in starch accumulating seeds such as maize
(Mechin et al. 2007). The expression of enolase during SE has been previously reported. Andriotis et al. (2010) found maximal amounts of enolase transcripts in torpedo embryos of Arabidopsis. Similarly, Lippert et al. (2005) detected a high expression of this protein only in the torpedo stage of Picea glauca, and therefore suggested that enolase could be an interesting candidate to be used as a molecular marker of embryogenesis maturation. In our study, enolase was also expressed only in the torpedo stage (Table 1), indicating that this protein could be used as a molecular marker of the torpedo stage in different plants.

Another protein identified involved in energy production was 2,3-bisphosphoglycerate-independent phosphoglycerate mutase (iPGAM) (spot CV31), which shows a phosphatase activity and is important for carbohydrate degradation and glycolysis (Graña et al. 1989; Collet et al. 2001). This protein, as enolase, was identified only in torpedo embryos and therefore represents another potential molecular marker of this stage.

Glyceraldehyde-3-phosphate dehydrogenase is a key enzyme of glycolysis; however, an additional role in the mediation of ROS signaling in plants has been proposed. Hancock et al. (2005) identified several proteins that might be potential targets of $\mathrm{H}_{2} \mathrm{O}_{2}$ in Arabidopsis, the most prominent of which was cGAPDH that is reversibly inhibited by $\mathrm{H}_{2} \mathrm{O}_{2}$. In our study, GAPDH was highly expressed in the globular phase and showed a reduced expression in the other SE stages. It is possible that the up-regulation of GAPDH may be related to the control of ROS in the globular phase. The up-regulation of cyclophilin (spot CV 4 and CV 5) in the globular and cotyledonary phases may also be related to the control of ROS levels. A higher expression of cyclophilin in the early stages of embryogenesis and in response to various stresses has been reported (Marivet et al. 1994; Scholze et al. 1999; Ruan et al. 2011), as well as its involvement in the control of ROS (Ruan et al. 2011). These results indicate that at the early development stages there may be a higher generation of ROS. Indeed, a higher activity of antioxidant enzymes such as superoxide dismutase, peroxidase and catalase has been reported in these stages (Kairong et al. 1999). Therefore, it is possible that a higher accumulation of ROS occurs in the globular stage and may account for the higher expression of GADP and cyclophilin to control ROS levels in the cell.

Isoforms of the storage globulin $11 \mathrm{~S}$ (spots CV 6 and CV 7) were also identified in this study. Globulins are the largest sources of protein reserve in dicotyledonous plant seeds (Shewry et al. 1995). The expression of spot CV 6 was higher in the torpedo phase than in the globular and cotyledonary phases, and CV 7 was not observed in the globular stage, showing a higher expression in the torpedo phase than in the cotyledonary phase. According to King and Gifford (1997), reserve proteins synthesized at the end of seed development are 
Table 1 Differentially expressed proteins identified by mass spectrometry analysis at the different stages of $C$. arabica somatic embryogenesis

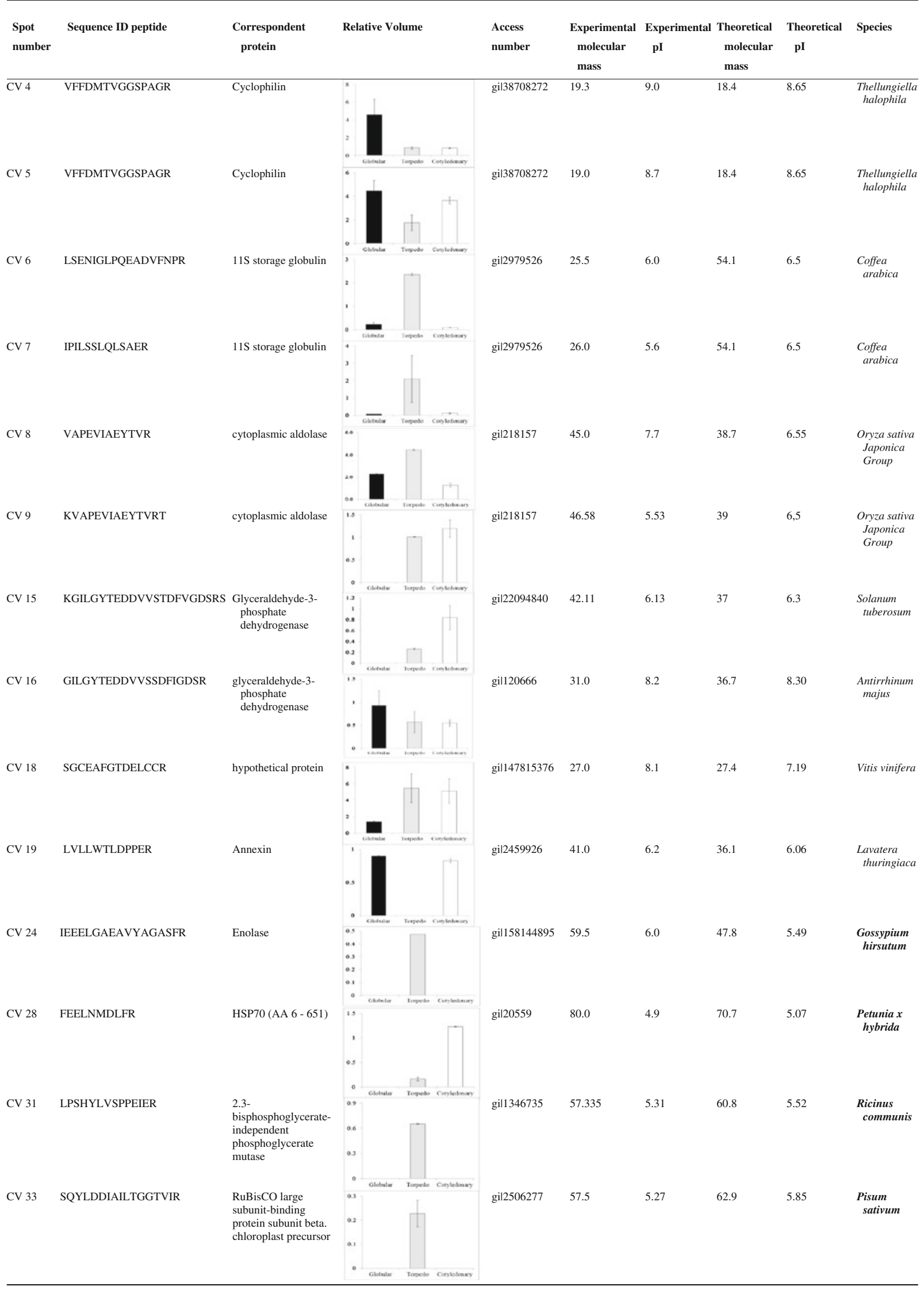




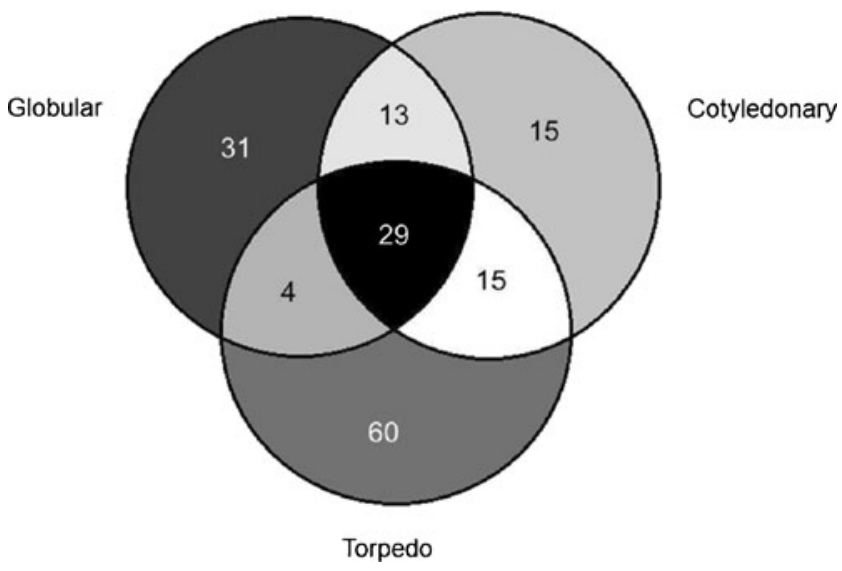

Fig. 2 Spots detected in the different somatic embryogenesis phases, as determined by the Bionumerics software v. 4.6 (Applied Maths NV, Belgium)

hydrolyzed during germination to serve as a source of nitrogen and amino acids for the plant. Therefore, the accumulation of this protein in the torpedo phase could be to guarantee the energy necessary during embryo maturation in the cotyledonary phase.

Proteins involved in stress response were also identified in our study. The molecular chaperone Heat Shock Protein 70 (HSP 70) (spot CV 28) was more abundant in the cotyledonary phase when compared to the torpedo stage, and was not observed in the globular stage. HSP 70 is a protein expressed under stress conditions and is essential for cellular recovery and normal functioning of the cell. This protein acts as a molecular chaperone, preventing protein denaturation (Zhu et al. 1993). Cytoplasmic aldolase is another protein related to stress conditions, induced in rice vegetative tissues in response to exogenous $\mathrm{ABA}$ and salinity (Karuna et al. 2000). This protein is also induced during zygotic embryogenesis and may be related to desiccation tolerance (Sghaier-Hammami et al. 2009). In the present study, this protein (spot CV 8) was expressed in the globular phase, up-regulated in the torpedo phase and downregulated in the cotyledonary phase.

Finally, the protein annexin was also identified in this study (spot CV19) and was observed only in the cotyledonary stage. Annexins are multifunctional proteins that play important roles in the cell (Gerke and Moss 2002). They interact with several membrane components that are involved in structural organization of the cell, acting in intracellular signaling and in growth control (Moss and Morgan 2004). Annexins have been identified in cotyledons of cassava somatic embryos undergoing secondary SE (Baba et al. 2008) and there is strong evidence that they are directly involved in cell division (Gallardo et al. 2003).

The examination of differentially expressed proteins in the three stages (globular, torpedo, and cotyledonary) of C. arabica cv. Catuaí Vermelho SE provided interesting insights into the SE process in coffee. Overall, during SE, a clear differential protein expression was observed in the different stages. Proteins related to stress response, maintenance of protein complexes in the chloroplasts, energy metabolism, intracellular signaling and growth control, as well as storage proteins, were identified. The results obtained in coffee are in agreement with the molecular model previously proposed, which showed that during SE a complex molecular system is turned on to control processes such as glycolysis, protein synthesis, cell division, ROS detoxification, among others. Our results also suggest that stress is an important factor that significantly contributes to SE. Changes in mRNA abundance of certain genes involved in oxidative stress and cell division during SE suggest that the arrangement of new cells into organized structures may depend on a genetically controlled balance between cellular proliferations and death (Thibaud-Nissen et al. 2003). An interesting outcome of these expression studies is the potential use of certain proteins as molecular markers for specific developmental stages or to differentiate embryogenic from non-embryogenic genotypes. The enolase and $11 \mathrm{~S}$ storage globulin proteins could be molecular marker candidates for somatic embryo developmental stages and for embryogenic and non-embryogenic genotype differentiation, respectively. Proteomic analyses are notoriously under-represented in the literature when compared to genomic studies; however, the comparison of protein expression data with that of transcriptomics and metabolomics will certainly help understand the embryogenesis process and allow the development of more effective SE protocols for different plant species.

Acknowledgements This research was supported by Consórcio Brasileiro de Pesquisa e Desenvolvimento do Café, Embrapa and UCB.

\section{References}

Andriotis VM, Kruger NJ, Pike MJ, Smith AM (2010) Plastidial glycolysis in developing Arabidopsis embryos. New Phytol 185:649-662

Baba AI, Nogueira FCS, Pinheiro CB, Brasil JN, Jereissati ES, Jucá TL, Soares AA, Santos MF, Domont GB, Campos FAP (2008) Proteome analysis of secondary somatic embryogenesis in cassava (Manihot esculenta). Plant Sci 175:717-723

Bian F, Zheng C, Qu F, Gong X, You C (2010) Proteomic analysis of somatic embryogenesis in Cyclamen persicum Mill. Plant Mol Biol Rep 28:22-31

Blum H, Beier H, Gross HJ (1987) Improved silver staining of plantproteins, RNA and DNA in polyacrylamide gels. Electrophoresis 8:93-99

Boxtel J, Berthouly M (1996) High frequency somatic embryogenesis from coffee leaves. Plant Cell Tissue Organ Cult 44:7-17

Bradford MM (1976) A rapid and sensitive method for the quantitation of microgram quantities utilizing the principle of protein dye binding. Anal Biochem 72:248-254

Collet JF, Stroobant V, Van Schaftingen E (2001) The 2,3-bisphosphoglycerate-independent phosphoglycerate mutase from 
Trypanosoma brucei: metal-ion dependency and phosphoenzyme formation. FEMS Microbiol Lett 204:39-44

de Mot R, Vanderleyden J (1989) Application of two dimensional protein analysis for strain fingerprinting and mutant analysis of Azospirillum species. Can J Microbiol 35:960-967

Fehér A, Pasternak TP, Dudits D (2003) Transition of somatic plant cells to an embryogenic state. Plant Cell Tissue Organ Cult 74:201-228

Gallardo K, Signor C, Vandekerckhove J, Thompson RD, Burstin J (2003) Proteomics of Medicago truncatula seed development establishes the time frame of diverse metabolic processes related to reserve accumulation. Plant Physiol 133:664-682

Gerke V, Moss SE (2002) Annexins: from structure to function. Physiol Rev 82:331-371

Görg A, Postel W, Domscheit A, Günther S (1988) Two-dimensional electrophoresis with immobilized $\mathrm{pH}$ gradients of leaf proteins from barley (Hordeum vulgare ): method, reproducibility and genetic aspects. Electrophoresis 9:691-692

Graña X, Ureña J, Ludevid D, Carreras J, Climent F (1989) Purification, characterization and immunological properties of 2,3bisphosphoglycerate-independent phosphoglycerate mutase from maize (Zea mays) seeds. Eur J Biochem 186:149-153

Hancock JT, Henson D, Nyirenda M, Desikan R, Harrison J, Lewis M, Hughes J, Neill SJ (2005) Proteomic identification of glyceraldehyde 3-phosphate dehydrogenase as an inhibitory target of hydrogen peroxide in Arabidopsis. Plant Physiol Biochem 43:828-883

Huang X, Lu X-Y, Zhao J-T, Chen J-K, Dai X-M, Xiao W, Chen Y-P, Chen Y-F, Huang X-L (2010) MaSERK1 gene expression associated with somatic embryogenic competence and disease resistance response in banana (Musa spp.). Plant Mol Biol Rep 28:309-316

Kairong C, Gengsheng X, Xinmin L, Gengmei X, Yafu W (1999) Effect of hydrogen peroxide on somatic embryogenesis of Lycium barbarum L. Plant Sci 146:9-16

Karuna SB, Rajendrakumar CS, Reddy AR (2000) Aldose reductase in rice (Oryza sativa L.): stress response and developmental. Plant Sci 160:149-157

King JE, Gifford DJ (1997) Amino acid utilization in seeds of loblolly pine during germination and early seedling growth. Plant Physiol 113:1125-1135

Laemmli UK (1970) Cleavage of structural proteins during the assembly of the head of bacteriophage T4. Nature 227:680-685

Li K, Zhu W, Zeng K, Zhang Z, Ye J, Ou W, Rehman S, Heuer B, Chen S (2010) Proteome characterization of cassava (Manihot esculenta Crantz) somatic embryos, plantlets and tuberous roots. Proteome Sci 8:10

Lippert D, Zhuang J, Ralph S, Ellis DE, Gilbert M, Olafson R, Ritland K, Ellis B, Douglas CJ, Bohlmann J (2005) Proteome analysis of early somatic embryogenesis in Picea glauca. Proteomics 5:461-473

Ma J, He Y, Wu C, Liu H, Hu Z, Sun G (2012) Cloning and molecular characterization of a SERK gene transcriptionally induced during somatic embryogenesis in Ananas comosus cv. Shenwan Plant Mol Biol Report 30:195-203
Marivet J, Margis-Pinheiro M, Frendo P, Burkard G (1994) Bean cyclophilin gene expression during plant development and stress conditions. Plant Mol Biol 26:1181-1189

Mechin V, Thevenot C, Le Guilloux M, Prioul JL, Damerval C (2007) Developmental analysis of maize endosperm proteome suggests a pivotal role for pyruvate orthophosphate dikinase. Plant Physiol 143:1203-1219

Moss SE, Morgan RO (2004) The annexins. Genome Biol 5:219.1-219.8

Pereira AR, de Carvalho SP, Pasqual M, Santos FC (2007) Embriogênese somática direta em explantes foliares de Coffea arabica $1 . \mathrm{cv}$. Acaiá Cerrado: efeito de cinetina e ácido giberélico. Ciênc Agrotec 31:332-336

Ruan SL, Ma HS, Wang SH, Fu YP, Xin Y, Liu WZ, Wang F, Tong JX, Wang SZ, Chen HZ (2011) Proteomic identification of OsCYP2, a rice cyclophilin that confers salt tolerance in rice (Oryza sativa L.) seedlings when overexpressed. BMC Plant Biol 11:34

Scholze C, Peterson A, Diettrich B, Luckner M (1999) Cyclophilin isoforms from Digitalis lanata: sequences and expression during embryogenesis and stress. J Plant Physiol 155: 212-219

Sghaier-Hammami B, Drira D, Jorrín-Novo JV (2009) Comparative 2DE proteomic analysis of date palm (Phoenix dactylifera L.) somatic and zygotic embryos. J Proteomics 73:161-177

Sharifi G, Ebrahimzadeh H, Ghareyazie B, Gharechahi J, Vatankhah E (2012) Identification of differentially accumulated proteins associated with embryogenic and non-embryogenic calli in saffron (Crocus sativus L.). Proteome Sci 10:3

Shevchenko A, Wilm M, Vorm O, Mann M (1996) Mass spectrometric sequencing of proteins silver-stained polyacrylamide gels. Anal Chem 68:850-858

Shewry PR, Napier JA, Tatham AS (1995) Seed storage proteins: structure and biosynthesis. Plant Cell 7:945-956

Thibaud-Nissen F, Shealy RT, Khanna A, Vodkin LO (2003) Clustering of microarray data reveals transcript patterns associated with somatic embryogenesis in soybean. Plant Physiol 132:118-136

Van Der Straeten D, Rodriguespousada RA, Goodman HM, Van Montagu M (1991) Plant enolase-gene structure, expression, and evolution. Plant Cell 3:719-735

Vieira L, Andrade A, Colombo C, Moraes A, Mehta A et al (2006) Brazilian coffee genome project: an EST-based genomic resource. Braz J Plant Physiol 18:95-108

Wold F, Ballou CE (1957) Studies on the enzyme enolase. J Biol Chem 227:301-328

Yang C, Zhao T, Yu D, Gai J (2011) Isolation and functional characterization of a SERK gene from soybean (Glycine max (L.) Merr.) plant. Mol Biol Rep 29:334-344

Zeng F, Zhang X, Zhu L, Tu L, Guo X, Nie Y (2006) Isolation and characterization of genes associated to cotton somatic embryogenesis by suppression subtractive hybridization and macroarray. Plant Mol Biol 60:167-183

Zhu JK, Shi J, Bressan RA, Hasegawa PM (1993) Expression Of An Atriplex nummularia gene encoding a protein homologous to the bacterial molecular chaperone DNA. J Plant Cell 5:341-349 